\title{
Identification of Primordial Germ Cells: Cytological, Histological and Immunohistochemical Aspects
}

\author{
Nazan Deniz Yön* and Cansu Akbulut \\ Department of Biology; Science and Letters Faculty; Sakarya University; Serdivan, Sakarya - Turkey
}

\begin{abstract}
Primordial germ cells (PGCs) constitute an embryonic cell type that migrate to gonadal precursors and form the gametes. In many animals, PGCs are set apart from somatic cells early during embryogenesis. These cells migrate to gonadal precursors and then constitute gonads so they are useful models for cell motility studies. They have a highlighted importance for development and reproduction studies. Primordial germ cells have morphological differences from the somatic cells. Structure of these cells can be detected with light and electron microscopy in early development stages. This review describes the morphological, histological, molecular and ultrastructural features of primordial germ cells in different animals and gives an overview for simplified identification.
\end{abstract}

Key words: Primordial germ cells, ultrastructure, histology, morphology

\section{INTRODUCTION}

Bisexually reproducing metazoans have two major lineages for two distinct lifestyle phases, i.e. soma and germ. Somatic cells form the body responsible for the individual life and are 'mortal'. Germ cells are 'immortal', because they are responsible for the species life via procuding gametes transmitting genetic information from one generation to the next (Xu et al. 2010). In many animals, the germ line can be identified as the cells which are morphologically different from the somatic cells in the early developmental period (Nagai et al. 2001). In worms, flies and frogs, a special cytoplasm called germ plasm or pole plasm (in flies) is located asymmetrically within the eggs and is inherited into some cells, which differentiate into germ cells (Nieuwkoop and Sutasurya 1979; Nagai et al. 2001). In Xenopus, germplasm containing the "'mitochondrial cloud"'aggregates in association with the reorganization of microtubulesafter fertilization (Ressom and Dixon 1988).
Primordial germ cells (PGCs) are germline stem cells that give rise to gametes in vertebrates. They originate outside the embryo very early in the development and migrate by a well-defined route into the genital ridges. During early embryogenesis in mammals, the PGCs are observed in an extra-embryonic region near the yolk sac, translocate to the endodermal epithelium of the hindgut as embryogenesis advances, and then separate from the gut epithelium to enter the dorsal mesentery, through which they finally migrate to form gonadal anlage (Soto-Suazo and Zorn 2005).

In many different organisms, primordial germ cells (PGCs) are specified in early development in an area which is an different position from gonad and then they migrate to gonadal precursors with amoeboid movements. In gonadal precursors they differentiate into gametes. Therefore, the cells have to reach the somatic part of the gonad in a process that, in addition to its crucial role in the propagation of the species, serves as a general

*Author for correspondence: ndy31@hotmail.com 
model for long-range cell migration (Raz 2006). PGCs found in the area between the entoderm and ectoderm, as well as those present in the blood vascular lumen, in general, are frequently spherical in profiles; the presence of pseudopodia is an occasional- finding for tPGCs (tissue PGCs) and gPGCs (gonadal PGCs). These characteristics indicate that migrating PGCs undergo morphological alterations in accordance with their localization (Fujimoto et al. 1975). These investigations showed the importance to study the development and reproduction.

PGCs which differentiate to germ cells, may arise epigenetically (Nagai et al. 2001) in urodeles (Nieuwkoop and Stasurya 1979; Michael 1984); mammals (Lawson and Hage 1994) and birds (Ginsburg 1994). In these animals, germ line cells can be identified only after the expression of morphological features of germ cells (Nagai et al. 2001). In teleost, PGCs have been investigated exclusively by both light and electron microscopy (Gevers et al. 1992; Kazama-Wakabayashi et al. 1999; Braat et al. 1999; Nagai et al. 2001). In many species including Drosophila, zebrafish and C. elegans, germ cells form in a specialized, maternally synthesized cytoplasm, which is thought to contain germ cell determinants. In contrast, inductive events play an essential role for germ cell specification in mammals (Stanz-Gaiano and Lehmann 2001).

Primordial germ cells show different features at different developmental stages. For example, migratory-stage PGCs exhibit a higher frequency of conversion into embryonic germ cells, pluripotent cells that resemble blastocyst-derived embryonic stem cells, than do PGCs in thegonads (Matsui et al. 1992; Resnick et al. 1992; Labosky et al. 1994). In addition, epigenetic changes characteristic to germline cells also occur in PGCs. Primordial germ cell migration is a useful model for cell motility studies. These cells follow a predetermined path during migration, which is directed by some genes and chemokines. Negative effects on the long migration route of primordial germ cells may prevent the development of the gonads, and may also cause structural and functional changes.

\section{MORPHOLOGICAL CHARACTERISTICS OF PGCs}

In most animals, structure of primordial germ cells are similar. PGCs are seperated by structural features from the circle shaped somatic cells. Primordial germ cells can be identified according to their structural (morphological) properties; round- oval shapes, large sizes, large nucleus, marked nuclear membrane and the typical electron dense structures (Nagai et al. 2001; Koç and Yüce 2012; Chilke 2012) (Fig. 1A). They can be characterized by high electron cytoplasm density and have a very irregular outline (Koç and Yüce 2012). They have a diameter of $10-20 \mu \mathrm{m}$ depending on species, stage and shape.

\section{HISTOLOGICAL CHARACTERISTICS}

Primordial germ cells are usually stained more densely than the peripheral somatic cells. Their peripheral cytoplasm shows high alkaline phosphatase activity, which is used as indicator enzyme (Koç and Yüce 2012). Alkaline phosphatase (an enzyme which is found in the cell or in the cell membrane and active at $\mathrm{pH}$ 8.5-10 with the ability of detaching phosphate groups) activity can be also observed in the peripheral cytoplasm of primordial germ cells (Koç and Yüce 2012) (Fig. 1B). They are more evident in Best Carmine (Fig. 1C) and PAS staining (Fig. 1D) because glycogen density are greater. In the Best Carmine and Periodic Acid Schiff (PAS) staining, dense red granular bodies can be identified in the cytoplasm of these cells. Also, the structures with granules known as "nuage materials" can be seen in the primordial germ cells studied with this staining methods. These cells have eosinophilic granules and give positive reaction with hematoxylin and eosin staining (Nagai et al. 2001; Koç 2008). Depending on the stage of development and systematic groups pigment granules of cytoplasm contain fat droplets and nutrient granules. In general, the cytoplasm, is dense and granular in appearance.

\section{IMMUNOHISTOCHEMICAL IDENTIFICATION}

The cytoplasm of PGC contains specific RNA and protein, such as vasa (Hay et al. 1988; Bardsley et al. 1993; Komiya et al. 1994). Vasa is a DEAD box (Asp-Glu-Ala-Asp) family gene that has been first identified in Drosophila melanogaster as a maternal determinant of germ cell formation (Raz 2000). Therefore, vasa and nanos genes can be used as a molecular marker for detecting PGCs (Fig. 2) (Koprunner et al. 2001; Akbulut et al. 2013). By isolating vasa gene from Drosophila, vasa-like DEAD-box RNA helicase gene could be 
isolated from the germ cells of mouse, rat, frog, zebra fish, planaria, chicken, silkworm and human (Raz 2000). Vasa homologous is found in vertebrates. Vasa gene expression have been identified in the germ cells of frogs (Komiya et al. 1994), mice (Fujiwara et al. 1994), rats (Komiya and Tanigawa 1995), chickens (Tsunekawa et al. 2000) and teleost fish (zebrafish, Yoon et al. 1997; Olsen et al. 1997; tilapia, Kobayashi et al. 2000). Another germ plasm component nanos RNA was also first identified in Drosophila (Koprunner 2001). It is known that nanos-like genes are required for early development of PGCs in different organisms. They have been identified in C. elegans (Subramaniam and Seydoux 1999), Xenopus laevis (Mosquera et al. 1993) and zebrafish (Koprunner 2001).

However, currently PGCs are most easily identified by using the monoclonal antibodies such as stage-specific embryonic antigens $\alpha$-SSEA-1 (Fox et al. 1981), $\alpha$-SSEA-3, SSEA-4 (Shevinski et al. 1982), EMA-1 (Hahnel and Eddy 1986) and TG-1 (Donovan et al. 1987), all of which bind glycoprotein molecules present on the surface of these cells. Of these, $\alpha$-SSEA- 1 is the most widely used marker for PGCs.

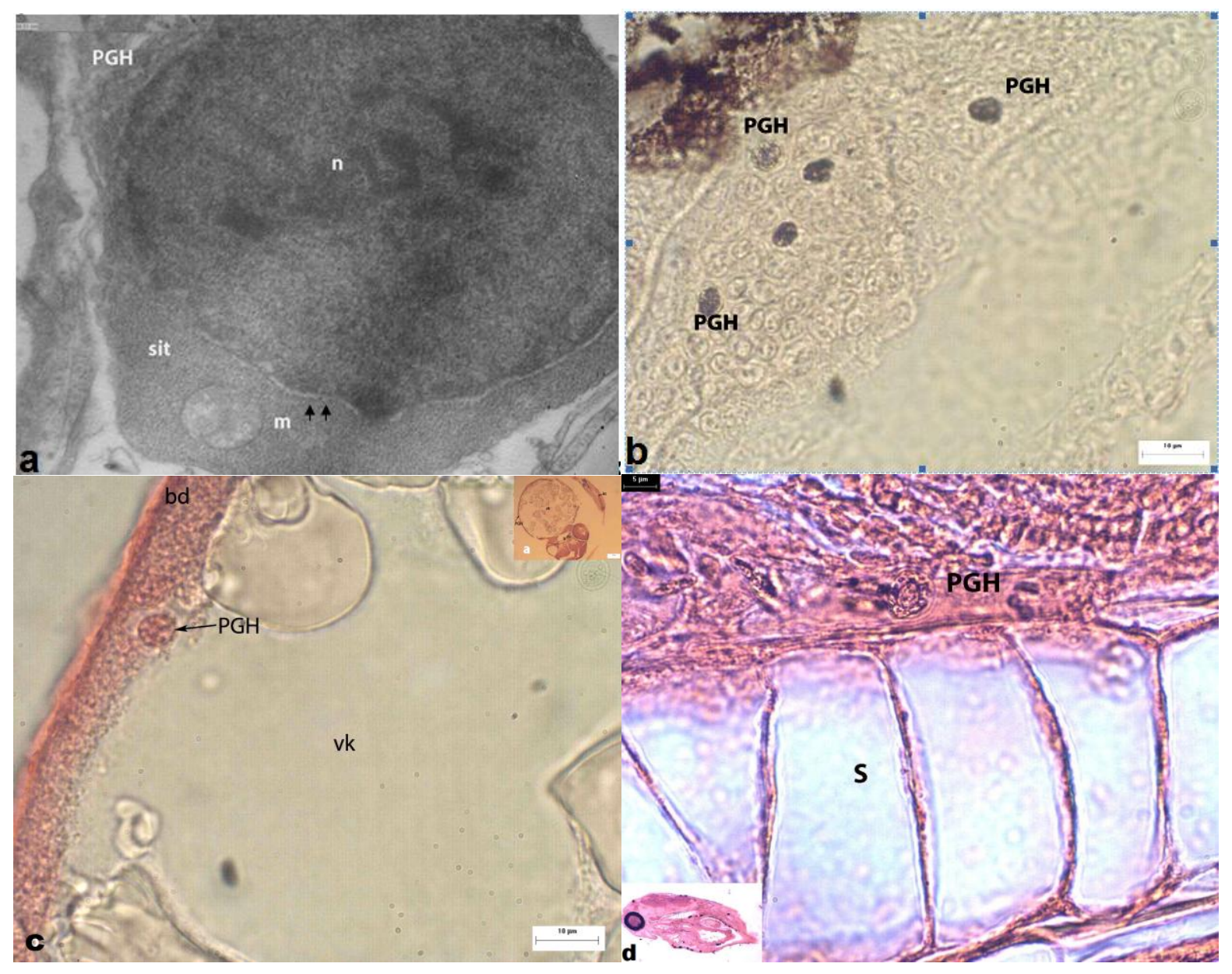

Figure 1 - Primordial germ cell at zebrafish larvae, a)Transmission electron microscopy, primordial germ cell (PGH), nucleus (n), cytoplasm (sit), mitochondria (m), nuage material (arrow). X30000 (Koç and Yuce 2012) b) Light microscopy, alkaline phosphatase staining, primordial germ cell (PGH), X100, (Koç, 2008) c) Light microscopy, best carmine staining, blastoderm (bd), primordial germ cell (PGH), yolk sac (vk), X100, (Koç, 2008) d) Light microscopy, Periodic Acid Schiff staining, somites (s), primordial germ cell (PGH), X100 (Koç, 2008). 


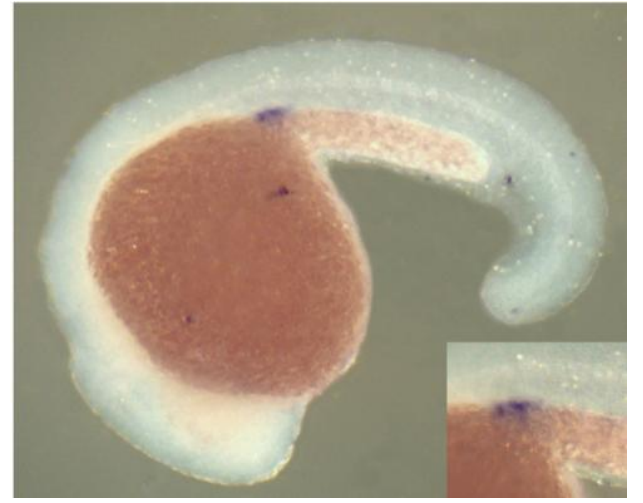

Figure 2 - Vasa positive primordial germ cells at $24 \mathrm{hpf}$ old zebrafish larvae, (Akbulut et al. 2013).

\section{CYTOLOGICAL FEATURES}

\section{Nuclear Characteristics}

In primordial germ cells, the nucleus is voluminous (nucleus/ cytoplasm) and eccentrically located. The outline of the nuclear envelope is irregular and the nucleoplasm contains widely dispersed chromatin. Each cell has a distinctive nuclear membrane. Chromatin are regularly distributed into the nuclei cytoplasm. Primordial germ cells appear large, having a large and spherical nucleus and numerous lipid droplets in the cytoplasm (Fuyuta et al. 1974; Yasuda et al. 1992).

\section{Ultrastructure of PGCs}

In the identification of primordial germ cells during the light microscopy stage, "nuage material" plays very important role due to its shape. This is a conserved feature of the germ cells in species across the animal kingdom. The "nuage" is distinct from germ plasma and under the electron microscope, appears as electron-dense granules localized to the cytoplasmic face of the nuclear envelope. There is currently a lack of information about the function of this material (Felici 2013). Many ribosomes are freely dispersed throughout the cytoplasm, making it very electrondense. Most round-shaped mitochondria and one or two centrioles are found in the cytoplasm of primordial germ cells (Koç and Yüce 2012) Yolk and oil particles in the cytoplasm are scattered haphazardly. Yolk and lipids are generally higher in content of PGCs at embryos and yolk shows a trend to decrease with the advancing stage in development (Fujimoto et al. 1975).
These cells experience slight morphological modifications depending on the migration phase in which they are observed. In the separation and migration phases, the PGCs are amoeboid in shape, and consequently, the nucleus attains a somewhat irregular contour (Soto-Suazo and Zorn 2005). Thus, PGCs are characterized with their pseudopodes particularly during migration. Electron microscopy studies have shown that, in these phases, PGCs have a conspicuous nucleolus, abundant glycogen particles, and lipid droplets as well as ribosomes and mitochondria (Soto-Suazo and Zorn 2005). In most organisms, including invertebrate species such as Drosophila and Caenorhabditis and nonmammalian vertebrates such as frogs and fishes, germ cell arises through the former mechanism. In the early stages of the development, these cells contain highly yolk granules and other features are not very dominant. Cytoplasm of primordial germ cells is called "germinal cytoplasm" or "germ plasma". Germ plasma is a maternally derived collection of cytoplasmic RNAs, RNA-binding proteins, and several organelles assemble within the mature oocyte and segregate during the first divisions of the embryo to the cells fated to become PGCs. In contrast, probably in all the mammals, PGCs arise shortly before or during gastrulation through a process of inductive signaling. Specific signals secreted by the neighboring cells induce the commitment and specification of PGC precursors among the epiblast cells before gastrulation. Shortly afterward, such precursors are determined as PGCs in an extraembryonic region (Felici 2013). Germ plasma contains cytoplasmic inclusions such as mitochondria, ribosomes and fibrils. For example, in Drosophila, germ plasma has a role in ensuring the function of germ cells (Findley et al. 2003). Germinal cytoplasm in all the lower vertebrates have a similar morphology. Germinal cytoplasm doesn't exist in mammalians (Francavilla et al. 1990; Lee et al. 1998; Lee et al. 2000).

PGCs are morphologically larger and usually located very close to the somatic cells (Fig. 3A), which are believed to modify or maintain the environment of these cells (Clark and Eddy 1975). In the separation phase, adherent junctions, desmosomes, and tight junctions are detected between these two cell types. During the migration phase, however, cytoplasmic bridges supplant the intercellular junctions connecting PGCs to the 
neighboring somatic cells (Fig. 3B) (Fujimotoet al. 1977, 1989; Pereda et al. 1988). The PGCs have pseudopodial cytoplasmic projections (Soto-Suazo and Zorn 2005).

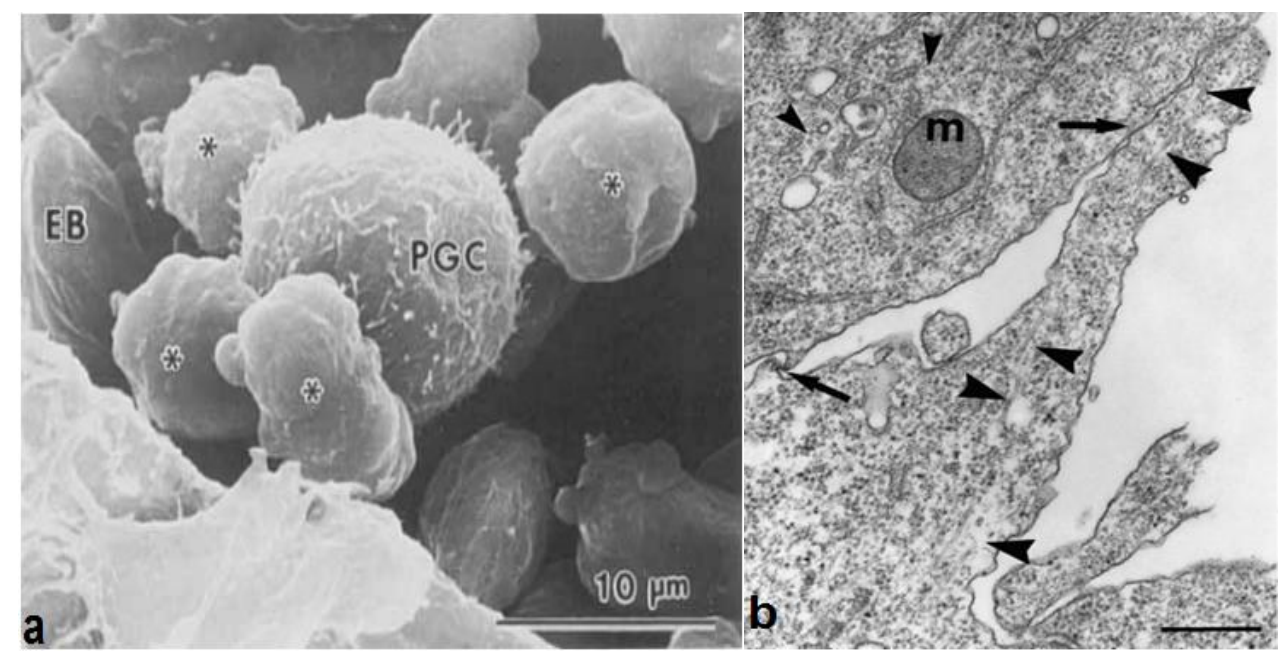

Figure 3 - a) SEM appearance of chick primordial germ cell, a)chick PGCs in a blood capillary of the blastoderm in an embryo at stage 11 PGCs are distinguishable from blood cells (asterisks) by their large size, and the numerous fine microvilli in their surface EB endothelium of blood vessel (Kuwana 1993) b) PGCin contact (arrows) with thecytoplasmic extension of anendodermal cell. Arrowheads,microtubules ; m, mitochondria. Bar,400 nm (Jaglarz and Howard 1995).

Primordial germ cells are elliptical or flat due to the direction of section. The nuclei of primordial germ cells covere the majority of the cytoplasm and their boundaries aregenerally irregular. Chromatin are distributed homogenously in the nucleus cytoplasm. The nucleolus is clear. The cytoplasm are dense and granular. Although there are ribosomes, glycogen granules and many mitochondria in the cytoplasm, endoplasmic reticulum and the Golgi complex are insufficiently developed. As compared with the surrounding somatic cells, there are differences in terms of size and structure. Primordial germ cells have more mitochondria compared to somatic cells. Also, electron-dense structures strik in the cytoplasm. These structures are not surrounded by a membrane. The structure of cytoplasm is thinfibrillary and reticular. Lipid droplets can be seen sporadically in the germinal cytoplasm. The nuage material are more dense around the mitochondria (Koç and Yüce 2012).

\section{FUNCTIONAL REGULATION MIGRATION}

OF

Some molecules have great importance in the migration of primordial germ cells to gonadal ridges. Of these, the most important one is stromal cell-derived factor 1 (SDF 1) which is a chemokine expressed from gonadal ridges. SDF 1 chemokine is the ligand of CXCR4 receptor which locates on the primordial germ cells (Doitsidou et al. 2002; Kunwar and Lehmann 2003; Molyneaux et al. 2003; Takeuchi et al. 2010). SDF1 and its Gprotein-coupled receptor CXCR4 are required for the normal migration of the primordial germ cells and SDF1/CXCR4 interaction is specifically required for the colonization of the gonads by primordial germ cells (Molyneaux et al. 2003). It has been shown that PGCs that do not receive the SDF-1 signal exhibit lack of directional movement toward their target and arrive at ectopic positions within the embryo (Doitsidou et al. 2002).

\section{CONCLUSION}

In this study, histological, ultrastructural and immunohistochemical aspects of primordial germ cells were evaluated. Classical studies about the germ cells are related to the proliferation and migration of these cells at embryonic and larval stages. Recently some studies about the PGCs have also been conducted. However, studies about 
PGCs remain at molecular level and the studies that explain the structural features are limited.

\section{REFERENCES}

Akbulut C, Kizil C, Yön ND. Effects of Low Doses of Bisphenol A on Primordial Germ Cells in Zebrafish (Danio rerio) Embryos and Larvae, Kafkas Univ Vet Fak Derg. 2013; 19(4): 647-653.

Bardsley A, McDonald K, Boswell RE. Distribution of tudor protein in the Drosophila embryo suggests separation of functions based on site of localization. Development. 1993; 119: 207-219.

Braat AK, Zandbergen T, Van de Water S, Goos HJTH, Zivkovic D. Characterization of zebrafish primordial germ cells: morphology and early distribution of vasa RNA. Dev Dyna. 1999; 216: 153-167.

Chilke AM. Development of Primordial Germ Cells (PGCs) in an Indian Freshwater Teleost, Labeo rohita (Hamilton). Eur J Exp Biol. 2012; 2(3): 631-640.

De Felici M. Origin Migration and Proliferation of Human Primordial Germ Cells. In: Giovanni Coticchio editor. Oogenesis. London: Springer; 2013. p. 19-37.

Doitsidou M, Reichmen-Freid M, Stebler J, Köprunner M, Dörries J, Meyer D, et al. Guidance of Primordial Germ Cell Migration by the Chemokine SDF-1. Cell. 2002; 111(5): 647-659.

Donovan PJ, Scott D, Godin I, Heasman J, Wylie CC. Studies on the migration of mouse germ cells. J Cell Sci. 1987; 8: 359-367.

Findley SD, Tamanaha M, Clegg NJ, Ruohola-Baker H. Maelstrom, a Drosophila spindle-class gene, encodes a protein that colocalizes with Vasa and RDE1/AGO1 homolog, Aubergine, in nuage. Development. 2003; 130: 859-871.

Fox N, Damjanov I, Martinez-Hernandez A, Knowel BB, Solter D. Immunohistochemical localization of the early embryonic antigen (SSEA-1) in postimplantation mouse embryos and fetal and adult tissues. Dev Biol. 1981; 83: 391-398.

Francavilla S, Cordeschi G, Properzi G, Concordia N, Cappa F, Pozzi V. Ultrastructure of Fetal Human Gonad Before Sexual Differentiation and During Early Testicular and Ovarian Development. $J$ Submicrosc Cytol Pathol. 1990; 22(3): 389-400.

Fujimoto T, Ukeshima A, Kiyofuji R. The Origin, Migration and Morphology of the Primordial Germ Cells in the Chick Embryo. Anat Rec. 1975; 185: 139154.

Fujimoto T, Miyayama Y, Fuyuta M. The origin, migration and fine morphology of human primordial germ cells, Anat Rec. 1977; 188: 315-330.
Fujimoto T, Ukeshima A, Miyayama Y, Kuwana T, Yoshinaga K, Nakamura, M. The primordial germ cells in amniotes: their migration in vivo and behavior in vitro. In: Motta PM editor. Developments in ultrastructure of reproduction. Rome: Antonio Delfino Editore; 1989. p. 13-22.

Fujiwara Y, Komiya T, Kawabata H, Sato M, Fujimoto $\mathrm{H}$, Furusawa $\mathrm{M}$ et al. Isolation of a DEAD-family protein gene that encodes a murine homolog of Drosophila vasa and its specific expression in germ lineage. Proceed Natl Acad Sci. 1994; 91: 1225812262.

Fuyuta M, Miyayama Y, Fujımoto T. Histochemical identifi cation of primordial germ cells in human embryos by PAS reaction. Okajimas Folia Anat Jap. 1974; 51(5): 251-262.

Gevers P, Duros J, Schipper H, Timmermans LPM. Origin of primordial germ cells, as characterized by the presence of nuage, in embryos of the teleost fish Barbus conchonius. Eur J Morphol. 1992; 30: 195204.

Ginsburg M. Primordial germ cells formation in bird. In: J Marsh, editor. Germline Development. Chichester: John Wiley \& Sons; 1994. p. 52-67.

Hahnel AC, Eddy EM. Cell surface markers of mouse primordial germ cells defined by two monoclonal antibodies. Gamete Res. 1986; 15: 1235-1244.

Hay B, Jan LY, Jan YN. A protein component of Drosophila polar granules is encoded by vasa and has extensive sequence similarity to ATP-dependent helicases. Cell. 1988; 55: 577-587.

Jaglarz MK, Howard KR. The active migration of Drosophila primordial germ cells. Development. 1995; 121: 3495-3503.

Kazama-Wakabayashi M, Yamaha E, Yamazaki F. The elimination and duplication of lower part of blastoderm effects on the number of primordial germ cells in goldfish. Fisheries Sci. 1999; 65: 577-582.

Kobayashi T, Kajiura-Kobayashi H, Nagahama Y. Differential expression of vasa homologue gene in the germ cells during oogenesis and spermatogenesis in a teleost fish, tilapia, Oreochromis niloticus. Mech Dev. 2000; 99: 139-142.

Koç ND. Effects of Deltamethrin on Primordial Germ Cell Migration of Zebrafish (Branchydanio rerio) Ph.D. Thesis: Marmara University Institute of Natural Sciences; 2008. p. 35-57.

Koç ND, Yuce R. A light- and electron microscopic study of primordial germ cells in the zebrafish (Danio rerio), Biol Res. 2012; 45: 331-336.

Komiya T, Tanigawa Y. Cloning of a gene of the DEAD box protein family which is specifically expressed in germ cells in rats. Biochem Biophys Res Commun. 1995; 207: 405-410. 
Komiya T, Itoh K, Ikenishi K, Furusawa M. Isolation and characterization of a novel gene of the DEAD box protein family which is specifically expressed in germ cells of Xenopus laevis. Dev Biol. 1994; 162: 354363.

Koprunner M, Thisse C, Thisse B, Raz E. A zebrafish nanos-related gene is essential for the development of primordial germ cells. Genes Dev. 2001; 15: 2877 2885.

Kunwar PS, Lehmann R. Developmental Biology Germ-cell attraction. Nature. 2003; 421: 226-227.

Kuwana T. Migration of Avian Primordial Germ Cells toward the Gonadal Anlage. Dev Growth Differ. 1993; 35(3): 237-243.

Labosky PA, Barlow DP, Hogan BLM. Mouse embryonic germ (EG) cell lines: transmission through the germ line and differences in the methylation imprint of insulin-like growth factor 2 receptor (Igf2r) gene compared with embryonic stem (ES) cell lines. Development. 1994; 120: 3197- 3204.

Lawson KA, Hage WJ. Clonal analysis of the origin of primordial germ cellsin the mouse. In: J Marsh, editor. Germline Development. Chichester: John Wiley \& Sons; 1994. p. 68-91.

Lee CK, Moore K, Scales N, Westhusin M, Newton G, Im KS, et al. Isolation and Genetic Transformation of Primordial Germ Cell Derived Cells from Cattle, Goats, Rabbits and Rats. Asian Aust J Anim Sci. 2000; 13: 587-594.

Lee CK, Scales N, Newton G, Piedrahita JA. Isolation and Initial Characterization of Primordial Germ Cell (PGC)- Derived Cells From Goat, Rabbit and Rats. Theriogenology. 1998; 49: 388.

Matsui Y, Zsebo K, Hogan BLM. Derivation of pluripotent embryonic cells from murine primordial germ cells in culture. Cell. 1992; 70: 841- 847.

Michael P. Are the primordial germ cells (PGCs) in Urodela formed by the inductive action of the vegitative yolk mass. Dev Biol. 1984; 103: 109-116.

Molyneaux KA, Zinszner H, Kunwar PS, Schaible K, Stebler J, Sunshine MJ, et al. The chemokine SDF1/CXCL12 and its receptor CXCR4 regulate mouse germ cell migration and survival. Development. 2003; 130: 4279-4286.

Mosquera L, Forristall C, Zhou Y, King ML. A mRNA localized to the vegetal cortex of Xenopus oocytes encodes a protein with a nanos-like zinc finger domain. Development. 1993; 117: 377-386.

Nagai T, Yamaha E, Arai K. Histological Differentiation of Primordial GermCells in Zebrafish. Zool Sci. 2001; 18: 215-223.

Nieuwkoop PD, Sutasurya LA. Primordial germ cells in the chordates:embryogenesis and phylogenesis. 1. ed. New York: CambridgeUniversity Press, 1979, 3p.

Olsen LC, Ausland R, Fojose A. A vasa-like gene in zebrafish identifies putative primordial germ cells. Mech Dev. 1997; 66: 95-105.
Pereda J, Posada J, Pozo J. Relación célula germinal primordial-célula somática en el epitelio intestinal humano Análisis ultraestructural. Arch Biol Med Exp. 1988; 21: 321.

Raz E. The function and regulation of vasa-like genes in germ-cell development. Gen Biol. 2000; 1(3): 1017.1-1017.6.

Raz E, Reichman-Fried M. Attraction rules: germ cell migration in zebrafish. Current Opin Genet Dev. 2006; 16: 355-359.

Resnick JL, Bixler LS, Cheng L, Donovan PJ. Longterm proliferation of mouse primordial germ cells in culture. Nature. 1992; 359: 550-551.

Ressom RE, Dixon KE. Relocation and reorganization of germ plasm in Xenopus embryos after fertilization. Development. 1988; 103: 507-518.

Santos AC, Lehmann R. Germ cell specification and migration in Drosophila and beyond. Curr Biol. 2004; 14: $578-589$

Shevinsky LH, Knowles BB, Damjanov I, Solter D. Monoclonal antibody to murine embryos defines a stage-specific embryonic antigen expressed on Mouse embryos and human teratocarcinoma cells. Cell. 1982; 30: 697-705.

Soto-Suazo M, Zorn TM. Primordial germ cells migration: morphological and molecular aspects. Anim Reprod. 2005; 2(3): 147-160.

Starz-Gaiano M, Lehmann R. Moving towards the next generation. Mech Dev. 2001; 105: 5-18.

Subramaniam K, Seydoux G. nos-1 and nos-2, two genes related toDrosophila nanos, regulate primordial germ cell development and survival inCaenorhabditis elegans. Development. 1999; 126: 4861-4871.

Takeuchi T, Tanigawa Y, Minamide R, Ikenishi K, Komiya T. Analysis of SDF-1/CXCR4 signsling in primordial germ cell migration and survival or differentiation in Xenopus laevis. Mech Dev. 2010; 127 (1-2): 146-158.

Tsunekawa N, Natio M, Sakai Y, Nishida T, Noce T. Isolation of chicken vasa homolog gene and tracing the origin of primordial germ cells. Development. 2000; 127: 2741-2750.

Xu HY, Ming You L, Jian Fang G, Yunhan H. Fish Germ Cells. Life Sciences. 2010; 53 (4): 435-446.

Yasuda Y, Tajima A, Fujimoto T, Kuwana TA. A method to obtain avian germ line chimeras using isolated primordial germ cells. J Reprod Fert. 1992; 96: 521-528.

Yoon C, Kawakami K, Hopkins N. Zebrafish vasa Homolog RNA is Localized to the Cleavage Planes of 2-and 4-Cell-Stage Embryos and Its Expressed in the Primordial Germ Cells. Development. 1997; 124: 3157-3166. 